\title{
Reproductive performance of dairy cows is influenced by prepartum feed restriction and dietary fatty acid source
}

\author{
M. G. Colazo, ${ }^{*}$ A. Hayirli, †‡ L. Doepel, $\dagger$ and D. J. Ambrose ${ }^{*} \dagger^{1}$ \\ *Dairy Research and Technology Centre, Alberta Agriculture and Rural Development, Edmonton, Alberta, T6H 5T6, Canada \\ †Department of Agricultural, Food and Nutritional Science, University of Alberta, Edmonton, Alberta, T6G 2P5, Canada \\ ‡Department of Animal Nutrition and Nutritional Disorders, Faculty of Veterinary Medicine, Ataturk University, Erzurum 25700, Turkey
}

\begin{abstract}
The objective of this study was to determine the effects of feed restriction and source of dietary fatty acids during the close-up dry period on postcalving reproductive performance of dairy cattle. Thirty-four days before expected calving, pregnant Holstein cows ( $\mathrm{n}=72$; parity 1 to 5 ) were randomly assigned to 1 of 6 treatments. Treatments were ad libitum (AL) or $24 \%$ feed restriction (FR) in combination with 1 of 3 oilseed supplements at $8 \%$ of diet dry matter: canola, linola, or flax to enrich the rations with oleic, linoleic, or linolenic fatty acids, respectively. After calving, cows were fed a common lactation diet that contained no oilseeds. Measurements of uterus, corpus luteum, and follicles were obtained by ultrasonography twice weekly from $7 \pm 1 \mathrm{~d}$ after calving until the first ovulation. Cows (n $=66)$ were subjected to timed artificial insemination (TAI), and pregnancy was determined $32 \mathrm{~d}$ later. Feedrestricted cows had lower dry matter intake and lost more body weight prepartum. Energy balance (Mcal/d) was negative in FR cows prepartum but they had a less severe negative energy balance postpartum. The dietary source of fatty acid did not affect energy balance. Cows fed AL had a higher incidence of uterine infections (10/37 vs. $2 / 35)$ but tended to have fewer ovarian cysts $(2 / 37$ vs. $7 / 35)$ than FR cows. Mean $( \pm \mathrm{SE})$ interval from calving to uterine involution did not differ among dietary treatments $(26.8 \pm 1.8 \mathrm{~d})$. Interval from calving to first ovulation was longer in cows fed canola than in those fed either linola or flax $(34.7 \pm 3.1$ vs. $23.7 \pm 3.2$ and $21.0 \pm 3.1 \mathrm{~d}$, respectively). A greater percentage of cows fed AL conceived to the first TAI (47.1 vs. 18.8) and tended to have fewer mean days open $(157 \pm 10.8$ vs. $191 \pm 10.1)$ than cows fed FR. In summary, FR cows had a lower incidence of uterine infections, but they were less fertile as reflected by a lower percent pregnancy to first TAI and increased days open. Cows
\end{abstract}

Received July 2, 2008.

Accepted January 28, 2009

${ }^{1}$ Corresponding author: divakar.ambrose@gov.ab.ca fed diets enriched in linoleic or linolenic fatty acids had a lesser incidence of ovarian cysts and ovulated sooner with no effect on energy balance or fertility.

Key words: dairy cow, dietary fatty acid, feed restriction, reproduction

\section{INTRODUCTION}

The transition period from late pregnancy to lactation is the most metabolically challenging time for the dairy cow. It is characterized by a decrease in DMI (Hayirli et al., 2002) and a significant increase in the nutrients required for fetal growth and milk production (Drackley, 1999). Following calving, most dairy cows enter a period of negative energy balance (NEBAL), the severity and duration of which is primarily related to DMI (Butler, 2000). In turn, NEBAL is associated with elevated plasma NEFA and hepatic lipid concentrations. Energy balance during the first weeks of lactation is highly correlated with the interval from calving to first ovulation (Beam and Butler, 1998; Butler, 2000), which may affect subsequent fertility (Thatcher and Wilcox, 1973).

Although maximizing DMI prepartum has traditionally been advocated, restricting DMI in the close-up dry period may actually have positive effects on postpartum DMI and cow health. Agenäs et al. (2003) reported that cows with restricted energy intakes during the dry period increased their postpartum feed intake and milk yield at faster rates than cows fed free choice. Such cows also had lower NEFA concentrations during the first 4 wk postpartum (Holtenius et al., 2003), suggesting that cows with reduced energy intake during the prepartum period have reduced mobilization of body fat, higher DMI, and a decreased incidence of periparturient problems (Beever, 2006).

The beneficial effects of postpartum dietary fatty acid supplementation on dairy cow reproductive function have been documented recently. In this regard, the inclusion of flax seed in postpartum diets improved fertility through reduced pregnancy losses (Ambrose et al., 2006). Thangavelu et al. (2007) have also shown 


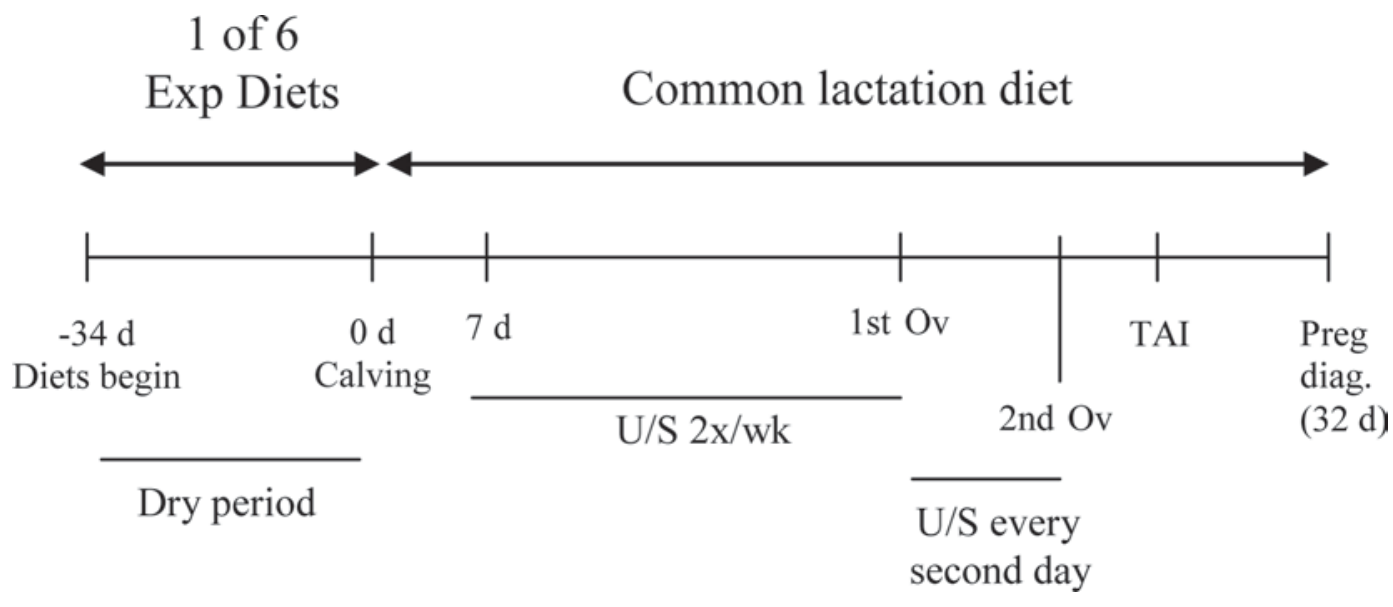

Figure 1. Experimental design. Holstein cows $(\mathrm{n}=72)$ were assigned to receive 1 of 6 experimental diets during the dry period, beginning approximately $34 \mathrm{~d}$ before calving. Cows were assigned to 1 of 2 levels of prepartum feed intake (either ad libitum or $24 \%$ restricted) and 1 of 3 types of oilseeds (canola, linola or flax) at $8 \%$ on DM basis. Ovarian changes were monitored by ultrasonography (U/S) twice weekly from 7 d after calving to the day of first ovulation (1st Ov). After a 65-d voluntary waiting period, cows underwent timed AI (TAI) after synchronization of ovulation.

that embryos of cows fed diets supplemented with unsaturated fatty acids of flax or sunflower seed origin had enhanced development, as evident by an increase in blastomere number, compared with those collected from cows fed diets supplemented with a saturated fat source. Ambrose et al. (2006) also reported an effect of dietary fatty acid on preovulatory follicle size with cows fed a diet enriched in linolenic acid having significantly larger follicles, suggesting that dietary long-chain fatty acids might influence follicle growth and resumption of postpartum cyclicity. The effects of diets enriched in certain long-chain fatty acids fed over the transition period (spanning the last few weeks prepartum up to 12 wk postpartum) on postcalving reproductive performance of dairy cows have also been investigated in a few recent studies (reviewed by Santos et al., 2008). However, whether prepartum dietary fatty acids influence resumption of cyclicity and postpartum reproductive performance needs further research. It is also not known if feeding diets enriched in specific unsaturated fatty acids during the prepartum period offers any carryover reproductive benefits postpartum. Thus, the objective of this study was to determine the effects of feed restriction and source of dietary fatty acids during the close-up dry period on postcalving reproductive performance of dairy cows. We hypothesized that 1) restricted feed intake during the prepartum period will improve postpartum DMI and reduce NEBAL, thereby contributing to improved reproductive performance, and 2) dietary inclusion of long-chain unsaturated fatty acids during the dry period will have a differential influence on resumption of cyclicity and carryover beneficial effects on fertility.

\section{MATERIALS AND METHODS}

\section{Animals and Diets}

The study was conducted at the Dairy Research Unit of the University of Alberta, Edmonton, Canada, between February 2006 and February 2007, with all animal experimental procedures approved by the University of Alberta Animal Care and Use Committee and animals cared for according to the Canadian Council of Animal Care (1993). Seventy-two Holstein cows of parity 1 to 5 (25 primiparous and 47 multiparous) were used. Thirtyfour days before the expected date of calving $(\mathrm{d}-34)$, animals were blocked by parity and expected calving date, and were randomly assigned within each block to 1 of 6 dietary treatments in a $2 \times 3$ factorial arrangement (Figure 1). The dietary treatments were 2 levels of feed intake: ad libitum (AL) or $24 \%$ feed restriction (FR), and 3 types of rolled oilseed supplements: canola (C), linola $(\mathbf{L})$, or flax $(\mathbf{F})$ at $8 \%$ of DM (Table 1) to enrich the rations with oleic (C 18:1), linoleic (C 18:2), or linolenic (C 18:3) acids, respectively. The FR was fully implemented by $\mathrm{d}-27$, and was based on the cows' ad libitum intake from $\mathrm{d}-34$ to $\mathrm{d}-31$. The oilseeds were rolled as described previously (Ambrose et al., 2006) before incorporation in the diet. After calving, cows were fed a common lactation diet containing no oilseeds (Table 1 ). The key fatty acid composition of the oilseeds is presented as a footnote to Table 1.

Energy balance estimates for pre- and postpartum periods were calculated as described by Rabelo et al. (2003). However, instead of using a fixed calf weight for calculating energy requirements of pregnancy, we used the actual birth weights of $47,48,50,51$, and $49 \mathrm{~kg}$, 
for parities $1,2,3,4$, and 5 , respectively. Calf BW was recorded immediately after calving.

Cows were housed in tie-stalls and had unrestricted access to water. They were fed once daily at $0930 \mathrm{~h}$, allowed $1 \mathrm{~h}$ of exercise each day (between 1030 and 1130 $\mathrm{h}$ ), and milked twice daily between 0400 and $0600 \mathrm{~h}$ and between 1530 and $1730 \mathrm{~h}$. Milk yield was recorded twice a day and orts were weighed daily before commencement of feeding. Rations were adjusted for DM content weekly based on DM content of the forages and concentrates. Cow BW and BCS were determined before treatment $(\mathrm{d}-34)$, and on $\mathrm{d} 1$ and $\mathrm{d} 56$ after calving. All BW, pre- and postpartum, were absolute, with no adjustments made for the weights of the fetus, fetal membranes, or fetal fluids. The same technician assigned BCS to each cow on a scale of 1 (emaciated) to 5 (overconditioned) (Edmonson et al., 1989).

\section{Sampling and Cow Health Monitoring}

Blood samples were collected into evacuated tubes containing sodium heparin (Vacutainer, Becton Dickinson and Co., Franklin Lakes, NJ) by puncturing a coccygeal blood vessel at approximately $1 \mathrm{~h}$ before feeding on $\mathrm{d}-34,-21,-7,-1,3,14$, and 28 relative to calving. Sample tubes were immediately placed on ice and centrifuged within $2 \mathrm{~h}$ at $4^{\circ} \mathrm{C}$ for 15 min at 3,300 $\times g$; plasma was separated and stored at $-20^{\circ} \mathrm{C}$ until analyzed for insulin, IGF-1, and NEFA.

During the study, cow health status was monitored and recorded daily by a technician. Retained fetal membranes (RFM) was defined as the lack of detachment of fetal membranes within $24 \mathrm{~h}$ after calving (Roberts, 1986). Cows with RFM were treated with antibiotics only if presenting with fever and inappetence. Milk fever was determined when animals, about the time of parturition, were disinclined to move and in sternal recumbency with muscular weakness and depression of consciousness (Radostits et al., 1994). Displacement of the abomasum (DA) was suspected in cows with inappetence and decreased milk production, and was confirmed by simultaneous percussion and auscultation over an area between the 9 th and 12 th ribs of the upper third of the abdominal wall (Radostits et al., 1994). Mastitis was defined as inflammation of the mammary gland with heat, pain, and induration detectable by manual palpation and confirmed by the California Mastitis Test (Schalm and Noorlander, 1957).

Postpartum uterine infections were identified based on purulent or mucopurulent uterine discharge within the first $2 \mathrm{wk}$ after calving or the presence of uterine fluid at ultrasonography on d 28 or 30 postpartum. Cows with purulent or mucopurulent uterine discharge within the first 2 wk after calving were treated with an-
Table 1. Ingredient and nutrient content of the diets

\begin{tabular}{lcc}
\hline Item & Precalving & Postcalving \\
\hline Ingredients, \% of DM & & \\
Alfalfa silage & 50.00 & 22.00 \\
Barley silage & 10.00 & 25.06 \\
Alfalfa hay & 7.27 & 10.00 \\
Barley grain & 8.00 & 22.34 \\
Oilseed & 5.34 & - \\
Soybean meal & - & - \\
Corn grain & - & 4.32 \\
Corn gluten meal & 17.60 & - \\
Oat hulls & & 1.07 \\
Canola meal & & 1.12 \\
Fish meal & & 2.04 \\
Vegetable oil & & 1.94 \\
Ca soap of fatty acids & & 0.39 \\
Molasses & & 0.83 \\
NaHCO & & 0.63 \\
Limestone & 1.79 & 1.75 \\
Mineral/vitamin premix ${ }^{2}$ & & \\
Nutrients & 1.68 & 1.73 \\
NE ${ }_{\mathrm{L}}^{3}{ }^{\text {Mcal } / \text { kg }}$ & 13.26 & 17.90 \\
CP & 41.45 & 32.50 \\
NDF & 25.49 & 21.24 \\
ADF & 5.95 & 5.49 \\
Fat & 0.59 & 1.33 \\
Ca & 0.38 & 0.48 \\
P & & \\
\hline
\end{tabular}

${ }^{1}$ Canola, linola, or flax; amounts of $\mathrm{C} 18: 1, \mathrm{C} 18: 2$, and $\mathrm{C} 18: 3$ (as \% of total fatty acid esters) were 51.2, 22.2, and 12.0 in canola seed; $12.5,71.7$, and 3.1 in linola seed; and $14.9,18.3$, and 55.8 in flaxseed, respectively.

${ }^{2}$ Supplied per kilogram of diet DM: Ca, 0.10\%; P, 0.60\%; Mg, 0.30\%; $\mathrm{Cl}, 58.00 \%$; K, 0.70\%; Na, 11.50\%; S, 0.23\%; Co, $6.20 \mathrm{mg}$; Cu, 1,170 mg; I, 80 mg; Mn, 3.10 g; Se, 25 mg; Zn, 5.00 g; vitamin A (1,000), 1,265 IU; vitamin $\mathrm{D}_{3}(1,000), 142 \mathrm{IU}$; vitamin E (1,000), 3,800 IU.

${ }^{3}$ Based on DMI of $12 \mathrm{~kg}$ precalving and $16 \mathrm{~kg}$ postcalving.

tibiotics only if presenting with fever and inappetence. All cows with uterine fluid determined by ultrasonography were given 2 doses (25 $\mathrm{mg}$ each) of dinoprost tromethamine $\left(\mathrm{PGF}_{2 \alpha}\right.$; Lutalyse, Pfizer Animal Health, Kirkville, Québec, Canada) 14 d apart.

\section{Reproductive Management}

The ovaries and uterus were examined by transrectal ultrasonography with a real time, B-mode scanner equipped with a 7.5-MHz linear-array transducer (Aloka SSD-500, Aloka Co., Tokyo, Japan). Measurements of uterine horns were obtained twice weekly from $7 \pm 1 \mathrm{~d}$ after calving to determine uterine involution (Sakaguchi et al., 2004). Ovarian follicular and corpus luteum (CL) dynamics were also examined twice weekly from $7 \pm 1$ $\mathrm{d}$ after calving to the day of first ovulation. Ovulation was confirmed by the absence of a large (diameter $\geq 10$ $\mathrm{mm}$ ) follicle that had been detected at the previous examination, and subsequent CL formation (Pierson and Ginther, 1984). Anovulatory follicles $\geq 25 \mathrm{~mm}$ in diameter that persisted for at least $10 \mathrm{~d}$ in the absence of a CL were defined as cysts (Garverick, 1997). 
After a voluntary waiting period of $65 \mathrm{~d}$, ovulation was synchronized (Pursley et al., 1995) in 66 cows by giving $100 \mu \mathrm{g}$ of GnRH (gonadorelin acetate; Fertiline, Vetoquinol Canada Inc., Lavaltrie, Québec, Canada) followed by $\mathrm{PGF}_{2 \alpha} 7 \mathrm{~d}$ later and a second $\mathrm{GnRH}$ (100 $\mu \mathrm{g})$ treatment $48 \mathrm{~h}$ after $\mathrm{PGF}_{2 \alpha}$ administration. All cows underwent timed AI (TAI) 14 to $18 \mathrm{~h}$ after the second GnRH administration with frozen-thawed semen. Ultrasonography was used to confirm pregnancy $32 \mathrm{~d}$ after TAI. Cows determined nonpregnant at pregnancy diagnosis were treated again for ovulation synchronization and inseminated unless culled. Cows were placed in TAI groups on a weekly basis, and all cows that remained open to the first TAI were given 3 more opportunities to conceive.

\section{Laboratory Analyses}

Plasma NEFA were determined colorimetrically (NEFA-C kit, Wako Chemicals USA Inc., Richmond, VA) with the modifications of Johnson and Peters (1993). Plasma insulin and IGF-1 concentrations were determined by RIA validated for bovines as described by Chelikani et al. (2004). Inter- and intraassay coefficients of variation were 10.6 and $7.1 \%$ for insulin and 11.0 and $8.4 \%$ for IGF-1, respectively.

\section{Statistical Analyses}

Dry matter intake, energy balance, and plasma insulin, IGF-1, and NEFA concentrations were analyzed using the MIXED procedure of SAS (version 9.1.2, 2004; SAS Institute Inc., Cary, NC). The model included block, level of intake, oilseed supplementation, time, and their interactions. The covariance structure of the repeated measurements for each variable that resulted in the lowest Akaike's information criteria and Bayesian information criteria was used (Littell et al., 1998). Plasma insulin, IGF-1, and NEFA concentrations on $\mathrm{d}-34$ were used to covariately adjust the data. Data for DMI were analyzed separately from $d-27$ until $d$ -1 (prepartum) and from d 1 until d 42 (postpartum). Data for energy balance was analyzed as for DMI but until d 56 postpartum.

Single mean comparisons, which include BW, BCS, interval from calving to the first ovulation and uterine involution, diameter of largest follicle at the first ultrasound examination, and days to first TAI were also analyzed by the MIXED model procedure. Bartlett's test of equal variance was used to analyze variance. Differences between treatments were determined using the PDIFF option of SAS.

The association between pregnancy status and dietary treatment groups, reproductive diseases, presence of follicular cyst, parity, and interval from calving to first ovulation and their interactions were analyzed using a general estimating equations method. The effects of dietary treatment on incidence of reproductive and metabolic diseases were also analyzed using a general estimating equations method. The level of intake was analyzed as a fixed effect with 2 categories (AL and FR), and the oilseed supplement was analyzed as a fixed effect with 3 categories $(\mathrm{C}, \mathrm{L}$, and $\mathrm{F})$. The model also included reproductive diseases (yes or no), follicular cyst (yes or no), lactation number $(1,2$, or $>2$ ), and interval from calving to first ovulation. Data were analyzed using the PROC GENMOD procedure of SAS. Model specifications included a binomial distribution, logit link function, repeated statement with subject equal to cow, and an exchangeable correlation structure. The main-effect model was assessed for the first-order interactions, where treatment and location or diet remained in the model. Model diagnostics included visual examination of the raw and standardized residuals. The residuals were plotted against predicted values of each observation. Rankit plots and WilkShapiro tests were used to assess the normality of the residuals. The ratio of the final-model deviance to the model degrees of freedom was also examined.

The days in milk to pregnancy were analyzed using the LIFETEST procedure in SAS. Values were censored when a cow was culled before becoming pregnant. Kaplan-Meier survival analysis was used to obtain a crude estimate of the effect of treatment on median days to pregnancy. Throughout this article, data are reported as least squares means \pm SEM for continuous variables. Probability values $\leq 0.05$ were considered significant, whereas $P>0.05$ but $\leq 0.10$ was considered a tendency.

\section{RESULTS}

\section{$D M I, B W$, and BCS}

During the prepartum period, the mean DMI of cows fed AL was $11.9 \mathrm{~kg} / \mathrm{d}$, significantly higher $(P=0.01)$ than the $9.0 \mathrm{~kg} / \mathrm{d}$ DMI of cows fed FR. The difference in DMI between AL and FR cows was $24.1 \%$ from d -27 to $\mathrm{d}-1$, and $27.9 \%$ from $\mathrm{d}-27$ to $\mathrm{d}-14$. However, there was a significant interaction $(P<0.02)$ between level of intake and time. The DMI in the last week prepartum declined to an average of $9.4 \mathrm{~kg}$ in the AL cows. There was also an interaction between level of intake and dietary fatty acid source on prepartum DMI, with intake of cows fed $\mathrm{C}$ highest in FR cows and lowest in AL cows (Table 2). During the postpartum period (d 1 to 42), intake tended to be different between the 2 intake groups (14.2 vs. 15.4 for AL and FR, respec- 
Table 2. The effect of dietary treatments on DMI $(\mathrm{kg} / \mathrm{d})$ during prepartum $(\mathrm{d}-27$ to -1$)$ and postpartum (d 1 to 42$)$ periods ${ }^{1}$

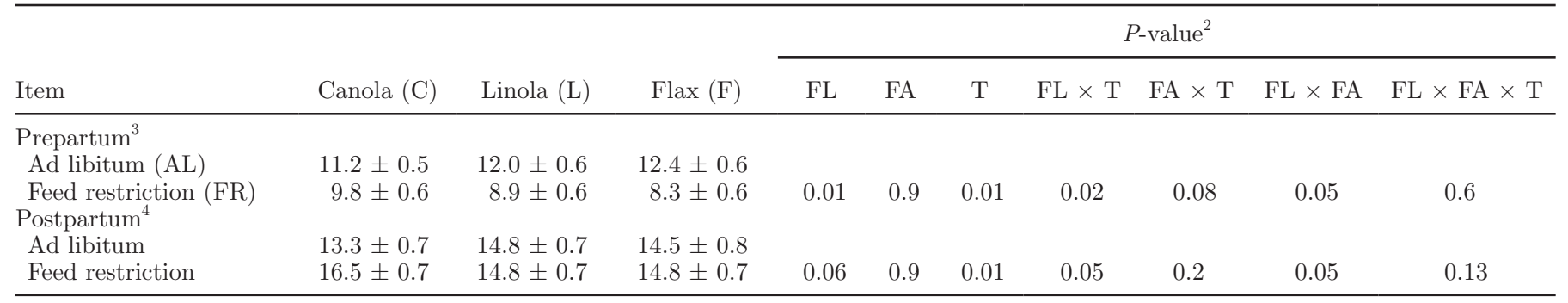

${ }^{1}$ Holstein cows $(\mathrm{n}=72)$ received 2 levels of prepartum feed intake, ad libitum (AL) or $24 \%$ feed restricted (FR) and 3 types of oilseeds (canola, linola, or flax) at $8 \%$ on DM basis to enrich the diets with oleic, linoleic, or linolenic acids, respectively. Probabilities of effects and their interactions included in the statistical model are shown.

${ }^{2} \mathrm{FL}=$ feed intake level $(\mathrm{AL}$ or $\mathrm{FR}) ; \mathrm{FA}=$ fatty acid supplementation; $\mathrm{T}=$ time.

${ }^{3} \mathrm{FL} \times$ FA interaction: ALC, ALF, and ALL vs. FRF and FRL, $P<0.01 ;$ ALF and ALL vs. FRC, $P<0.01 ; \mathrm{FRC}$ vs. FRF, $P<0.05$.

${ }^{4} \mathrm{FL} \times$ FA interaction: FRC vs. ALC, $P<0.01 ; \mathrm{FRC}$ vs. ALF, $P=0.06 ; \mathrm{FRC}$ vs. FRF, FRL, and ALL, $P=0.09$.

tively; $P=0.06)$. The difference between the groups was mainly observed from d 26 to 42 . As observed in the prepartum period, there was an interaction $(P=$ 0.05 ) between level of intake and fatty acid supplement in the postpartum period, again with intake of cows fed $\mathrm{C}$ being highest in FR cows and lowest in AL cows.

The effects of dietary treatment on mean BW and $\mathrm{BCS}$ on $\mathrm{d}-34$, d 1 , and $\mathrm{d} 56$ (d $0=$ calving) are shown in Table 3. Although mean BW did not differ among cows due to prepartum feeding regimen, FR cows lost more $(P<0.01)$ BW between $\mathrm{d}-34$ and $\mathrm{d} 1$ than cows fed AL. On the contrary, BW loss between $\mathrm{d} 1$ and 56 in cows fed AL was numerically higher $(P=0.12)$ than in FR cows. During the prepartum period BW loss was not affected by fatty acid source but cows fed $\mathrm{C}$ lost more $(P<0.05)$ BW between $\mathrm{d} 1$ and 56 than cows fed $\mathrm{L}$ or $\mathrm{F}$. Cows in the FR group tended $(P=$ 0.09 ) to have lower BCS at $d 1$ than those in AL group. Furthermore, the difference in BCS units between d
-34 and $d 1$ were $0.01 \pm 0.02$ and $-0.07 \pm 0.04$ for $\mathrm{AL}$ and FR cows, respectively $(P=0.07)$. The mean BCS did not differ between AL and FR cows on d 56 .

\section{Energy Balance, Milk Production, and Calf Weight}

Prepartum energy balance (Mcal/d) was higher in AL than in FR cows $(3.6 \pm 0.3$ vs. $-0.4 \pm 0.4 ; P<$ 0.01 ) but fatty acid source (oilseed) in the diet had no influence on energy balance. A time (wk) effect and time by level of intake interactions were evident $(P<$ 0.01), with FR cows attaining a deeper state of NEBAL than AL cows between 4 and 2 wk before calving. Energy balance during the postpartum period was also affected $(P<0.01)$ by level of intake $(-7.0 \pm 0.7$ vs. $-4.6 \pm 0.7$, for $\mathrm{AL}$ and FR, respectively) and time, but no interaction was detected. As in the prepartum period, fatty acid source did not affect energy balance during the postpartum period.

Table 3. Effects of dietary treatment on BW $(\mathrm{kg})$ and $\mathrm{BCS}^{1}$

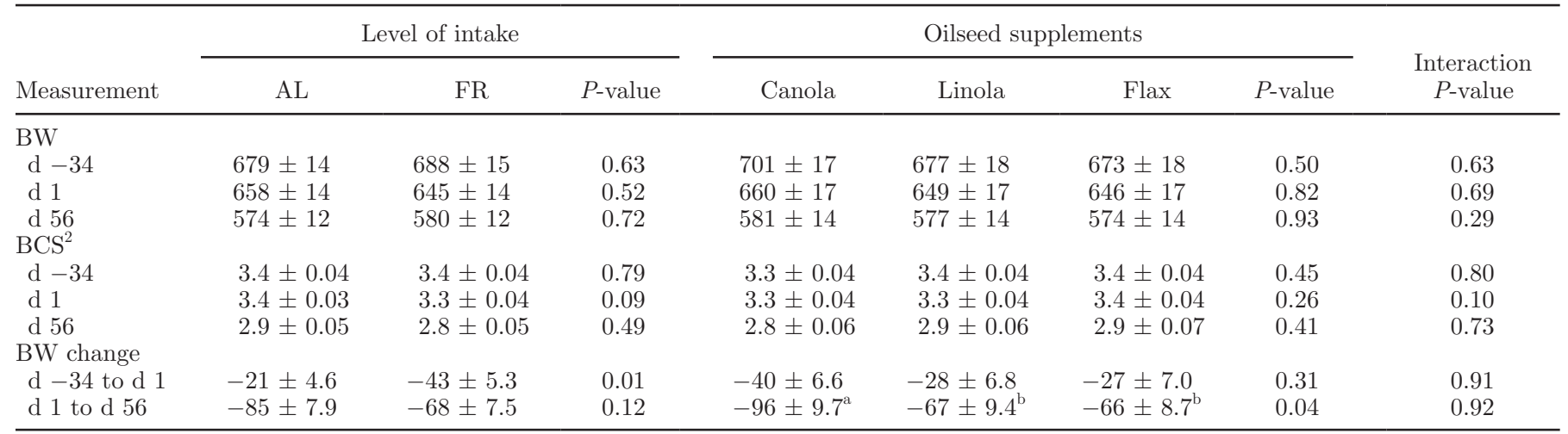

a,b Values with different superscripts differ at the $P$-value shown.

${ }^{1}$ Holstein cows $(\mathrm{n}=72)$ received 2 levels of prepartum feed intake, ad libitum $(\mathrm{AL})$ or $24 \%$ restricted $(\mathrm{FR})$ and 3 types of oilseeds (canola, linola, or flax) at $8 \%$ of dietary DM to enrich the diets with oleic, linoleic, or linolenic acids, respectively.

${ }^{2}$ BCS: 1 to 5 scale; 1 = emaciated, 5 = overconditioned (Edmonson et al., 1989). 
Milk production was not affected by FR but was influenced $(P<0.05)$ by the source of dietary fatty acid, with cows fed $\mathrm{C}, \mathrm{L}$, and $\mathrm{F}$ producing an average of 32.9, 36.4 , and $34.6 \mathrm{~kg} / \mathrm{d}$, respectively.

The mean BW of calves at birth was $48.3 \pm 0.9 \mathrm{~kg}$, and calf weight was not affected by either level of intake or fatty acid source.

\section{Plasma Hormones and Metabolites}

Overall mean plasma insulin concentration during the pre- and postpartum periods was higher $(P<0.01)$ in cows fed $\mathrm{AL}(4.9 \pm 0.2 \mu \mathrm{IU} / \mathrm{mL})$ than in those fed FR $(3.6 \pm 0.2 \mu \mathrm{IU} / \mathrm{mL})$ and tended $(P=0.09)$ to be higher with the $\mathrm{C}$ and $\mathrm{L}$ treatments compared with $\mathrm{F}$ (4.4, 4.6, and $3.7 \pm 0.3 \mu \mathrm{IU} / \mathrm{mL}$ for $\mathrm{C}, \mathrm{L}$, and $\mathrm{F}$, respectively). In the prepartum period, insulin was lower for cows in the FR group than for those in the AL group, whereas in the postpartum period, there was no difference between the 2 groups. Similarly, insulin concentration was lowest in the prepartum period for cows fed $\mathrm{F}$, whereas there were no differences between the 3 oilseed treatments in the postpartum period. There was also a significant interaction $(P<0.01)$ between prepartum intake level and fatty acid source on insulin concentrations. Cows fed AL and supplemented with C had the highest insulin concentrations $(5.9 \pm 0.4 \mu \mathrm{IU} /$ $\mathrm{mL}$ ). Conversely, cows in the FR group supplemented with either $\mathrm{C}$ or $\mathrm{F}$ had the lowest insulin concentrations $(2.8 \pm 0.3$ and $3.2 \pm 0.4 \mu \mathrm{IU} / \mathrm{mL})$. Cows fed $\mathrm{AL}$ supplemented with $\mathrm{F}$ or $\mathrm{L}(4.3 \pm 0.4$ and $4.4 \pm 0.3$ $\mu \mathrm{IU} / \mathrm{mL}$ ) and those fed FR supplemented with L (4.7 $\pm 0.4 \mu \mathrm{IU} / \mathrm{mL}$ ) were intermediate. The interactions of prepartum intake level and time, and fatty acid source and time were also significant $(P<0.01)$ for insulin concentration. Unlike insulin, plasma IGF-1 concentrations were not affected by prepartum intake level (52.9 \pm 1.9 and $53.7 \pm 1.9 \mathrm{ng} / \mathrm{mL}$ for $\mathrm{AL}$ vs. FR) or fatty acid source $(52.2 \pm 2.3,54.4 \pm 2.3$, and $53.3 \pm 2.4 \mathrm{ng} /$ $\mathrm{mL}$ for $\mathrm{C}, \mathrm{L}$, and $\mathrm{F}$, respectively).

Plasma concentrations of NEFA $(\mu \mathrm{Eq} / \mathrm{L})$ were unaffected by dietary treatments (overall mean $\pm \mathrm{SE}, 686.8$ $\pm 30.4)$, although there was a tendency $(P=0.06)$ for a fatty acid source $\times$ time interaction due to higher concentrations on $\mathrm{d}-1$ and 3 for $\mathrm{C}$ compared with $\mathrm{L}$ and $\mathrm{F}$.

\section{Health and Reproduction}

The effects of dietary treatments on the incidence of early postpartum reproductive and metabolic disorders are shown in Table 4. More cows $(P=0.01)$ in the AL group were diagnosed with uterine infections compared with the FR group. In contrast, ovarian cysts tended
Table 4. The effect of dietary treatments on the incidence of early postpartum reproductive and metabolic disorders ${ }^{1}$

\begin{tabular}{lrrrrr}
\hline & \multicolumn{5}{c}{ Dietary treatment } \\
\cline { 2 - 6 } Item $^{2}$ & AL & FR & Canola & Linola & Flax \\
\hline Cows, n & 37 & 35 & 24 & 24 & 24 \\
RFM & 2 & 5 & 2 & 2 & 3 \\
Uterine infections & $10^{\mathrm{a}}$ & $2^{\mathrm{b}}$ & 4 & 4 & 4 \\
Ovarian cyst & $2^{\mathrm{c}}$ & $7^{\mathrm{d}}$ & 6 & 2 & 1 \\
Milk fever & 4 & 1 & 3 & 1 & 1 \\
DA & 2 & 1 & 1 & - & 2 \\
Mastitis & 4 & 3 & 3 & 2 & 2 \\
\hline
\end{tabular}

${ }^{a, b}$ Numbers within a row with different superscripts differ at $P<$ 0.01 .

${ }^{c, \mathrm{~d}}$ Numbers within a row with different superscripts differ at $P=$ 0.09 .

${ }^{1}$ Holstein cows $(\mathrm{n}=72)$ received 2 levels of prepartum feed intake, ad libitum (AL) or $24 \%$ restricted (FR), and 3 types of oilseeds (canola, linola, or flax) at $8 \%$ on DM basis to enrich the diets with oleic, linoleic, or linolenic acids, respectively.

${ }^{2} \mathrm{RFM}=$ retained fetal membranes; $\mathrm{DA}=$ displacement of the abomasum.

$(P<0.09)$ to be lower in cows fed AL versus FR. However, the incidence of ovarian cysts was not affected by the source of fatty acids. In addition, the incidence of RFM, milk fever, DA, or mastitis did not differ among dietary treatments.

The effects of dietary treatments on follicular size and on intervals from calving to uterine involution and first ovulation are shown in Table 5. The interval from calving to uterine involution was not affected by any of the dietary treatments. All cows ovulated by $70 \mathrm{~d}$ after calving. Although the interval from calving to first ovulation was not affected by prepartum feed intake level, cows fed $\mathrm{C}$ had a longer interval than those fed $\mathrm{L}$ or $\mathrm{F}(P=0.02)$. The proportion of cows ovulating the first dominant follicle was not affected by dietary treatments (data not shown). However, FR cows had a numerically higher $(P=0.12)$ proportion of shorter estrous cycles ( $<17 \mathrm{~d}$ long) than those fed AL (data not shown). The cumulative ovulation rates of cows as influenced by oilseed type are shown in Figure 2.

Only 66 of the 72 cows were TAI; 5 cows were culled (4 due to mastitis, 1 due to lameness) and 1 cow died before first TAI. Out of those 6 cows, 5 were fed C. Therefore, the percentage of cows subjected to TAI was lower $(P<0.02)$ in $\mathrm{C}(79.2)$ than in $\mathrm{F}(100)$, and tended $(P=0.08)$ to be lower than in $\mathrm{L}(95.8)$. The percentage of cows subjected to TAI was not different between AL and FR groups (91.9 and 91.4, respectively). Percent pregnancy to first TAI was not affected by the presence of follicular cyst or by the interval from calving to first ovulation. However, cows on the AL diet had a higher $(P=0.02)$ percent pregnancy to the first TAI (Table $5)$ and, consequently, tended to have fewer $(P=0.08)$ days open than those on the FR diet (Figure 3). In 


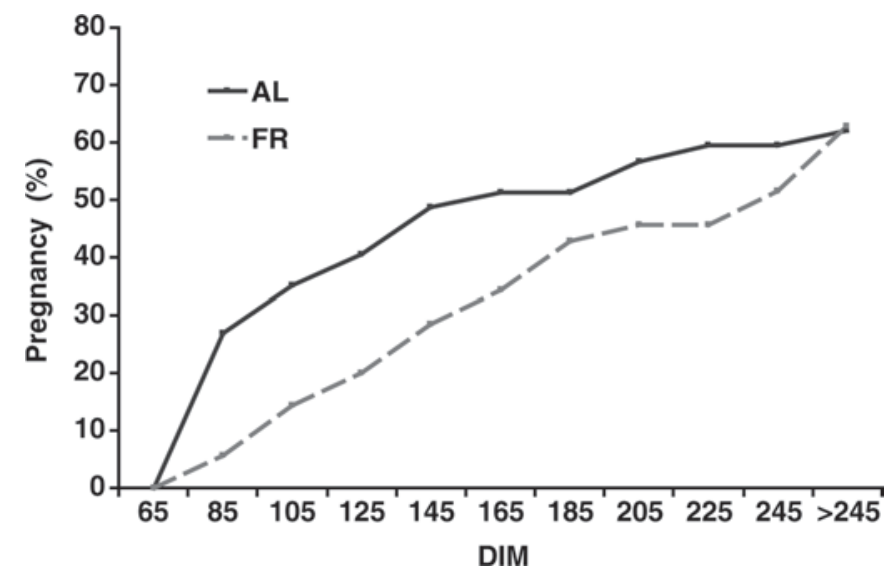

Figure 3. Cumulative proportion of pregnant Holstein cows $(\mathrm{n}=$ 66) fed ad libitum (AL) or $24 \%$ feed restricted (FR) for $27 \mathrm{~d}$ before calving (dry period).

addition, percent pregnancy to first TAI was greater $(P<0.05)$ in first-lactation cows $(56.5)$ than cows with 2 (11.8) or more (27.0) lactations, and tended to be greater $(P=0.10)$ in cows without uterine infections (36.4 vs. 18.2).

\section{DISCUSSION}

Previous studies reported that cows with restricted energy intakes during the dry period had increased postpartum feed intake $2 \mathrm{wk}$ after calving, lower loss of BW (Agenäs et al., 2003), and lower NEFA concentrations during the first weeks postpartum (Holtenius et al., 2003) compared with cows with high energy intakes. Therefore, we hypothesized that restricted feed intake during the prepartum period would improve postpar-

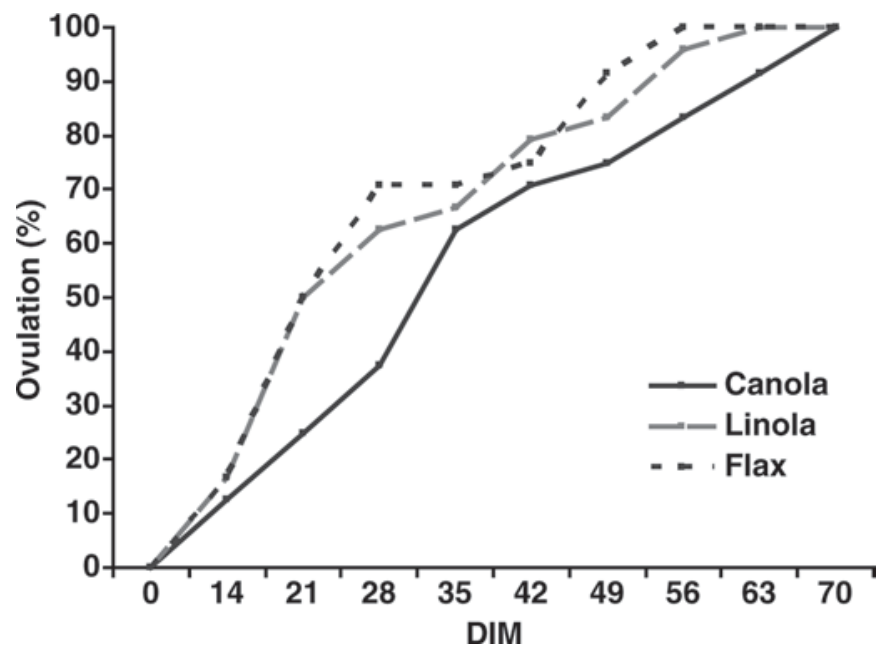

Figure 2. Cumulative proportion of first ovulation from calving to $70 \mathrm{~d}$ in Holstein cows $(\mathrm{n}=72)$ fed rolled canola, linola, or flax seed at $8 \%$ of diet DM for $34 \mathrm{~d}$ before calving.

tum DMI and reduce NEBAL, thereby contributing to improved reproductive performance. In support of our hypothesis, FR cows tended to have higher DMI and had less pronounced NEBAL after calving compared with cows fed AL, but the resumption of cyclicity was not significantly affected by prepartum feed intake level. In addition, percent pregnancy to first TAI was lower in FR cows, resulting in a tendency for longer days open in that group.

Following calving, most dairy cows enter a period of NEBAL, which is characterized by mobilization of NEFA from adipose tissue (Drackley, 1999). Hence, plasma NEFA concentrations and BCS are indicators of energy status, with a state of NEBAL being associated

Table 5. Effects of dietary treatments on reproductive performance ${ }^{1}$

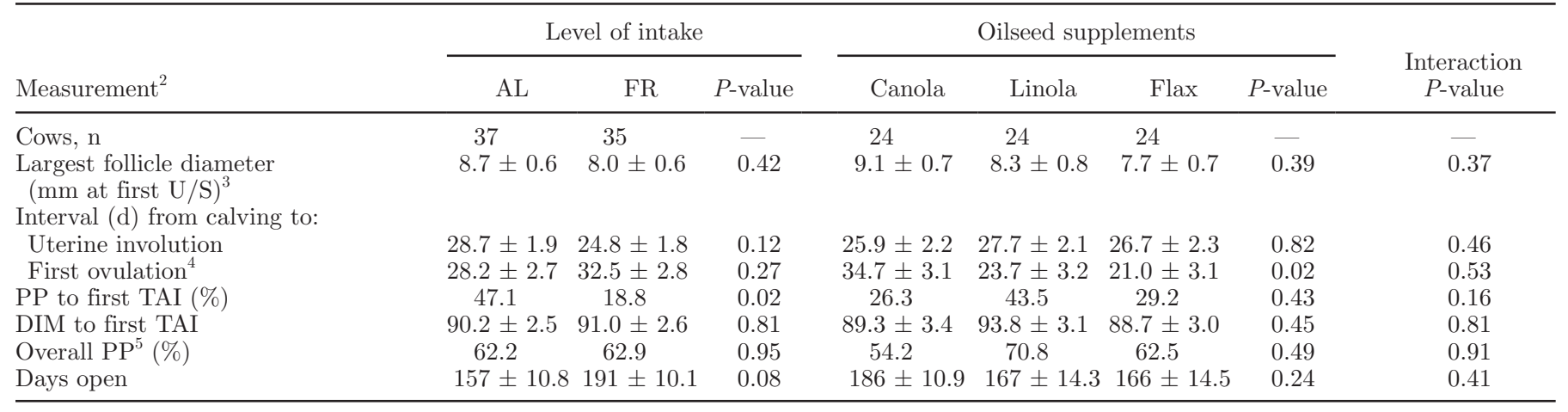

${ }^{1}$ Holstein cows $(\mathrm{n}=72)$ received 2 levels of prepartum feed intake, ad libitum (AL) or $24 \%$ restricted (FR), and 3 types of oilseeds (canola, linola, or flax) at $8 \%$ on DM basis to enrich the diets with oleic, linoleic, or linolenic acids, respectively.

${ }^{2} \mathrm{U} / \mathrm{S}=$ ultrasonography; $\mathrm{TAI}=$ timed $\mathrm{AI} ; \mathrm{PP}=$ percent pregnancy.

${ }^{3}$ First U/S was performed $7 \pm 1 \mathrm{~d}$ after calving.

${ }^{4}$ Canola $>$ linola and flax.

${ }^{5}$ Cumulative PP from 75 to 280 d postpartum. 
with delayed resumption of ovarian activity and low conception rate (Butler, 2000). Many other studies have intended to relate blood metabolite measurements and BCS in lactating dairy cows to subsequent reproductive outcomes (Beam and Butler, 1998; Pryce et al., 2001; Wathes et al., 2007a). Recently, Wathes et al. (2007a) investigated the relationships between metabolic parameters and fertility in dairy cows, using data from 4 studies. In primiparous cows, longer calving to conception intervals were associated with increased BCS prepartum and with significant BCS loss by 7 wk postpartum. In contrast, longer calving to conception intervals in multiparous cows were associated with reduced NEFA prepartum and reduced IGF-1 at 2 wk postpartum. However, in our study, the low fertility observed in FR cows was not related to BCS or plasma NEFA or IGF-1 concentrations. Furthermore, our finding suggests that lipid mobilization did not differ between $\mathrm{FR}$ and $\mathrm{AL}$ cows, although the former lost more BW and entered a state of NEBAL during the prepartum period. The negative effect of feed restriction on fertility was more evident at first TAI without increasing the interval to first ovulation, indicating that the carryover effect on fertility was through a likely impairment of oocyte competence. Indeed, it has been hypothesized that follicles growing under a period of NEBAL may contain oocytes of inferior quality (Britt, 1992). Considering that approximately $90 \mathrm{~d}$ are required for a follicle to grow from primary to preovulatory stage (Lussier et al., 1987), we believe that the negative consequences on fertility in cows subjected to prepartum feed restriction abated with time (i.e., in subsequent services). In support of this, the cumulative percent pregnancy from 75 to 280 $\mathrm{d}$ postpartum was not different between $\mathrm{FR}$ and $\mathrm{AL}$ cows, although FR cows tended to have significantly longer days open.

Although the incidence of ovarian cysts tended to be higher in FR cows, it was not a contributing factor to lower pregnancy in those cows because there was no statistical evidence of a negative effect of ovarian cysts on fertility. Many factors are associated with the development of ovarian follicular cyst in cattle including RFM, metritis, delayed uterine involution (Peter, 2004), reduced LH pulsatility associated with NEBAL (Ribadu et al., 2000), and hypoinsulinemia (Vanholder et al., 2005) postpartum. However, from our results, none of the aforementioned factors could be attributed to the slightly higher incidence of ovarian follicular cyst in FR cows. In this regard, the incidence of uterine infections was, in fact, lower in FR than in AL cows, and FR cows experienced a less severe NEBAL postpartum than AL cows; hence, uterine infections and reduced LH pulsatility associated with NEBAL were not predisposing factors in our study. Furthermore, plasma insulin concentrations during the postpartum period were not different between FR and AL cows although prepartum insulin concentrations were lower in FR cows. In addition, although not significantly different, the incidence of ovarian cyst in FR cows fed $\mathrm{C}$ was higher $(45.4 \%)$ than in $\mathrm{AL}$ cows fed $\mathrm{C}(7.7 \%)$. Incidentally, the FR cows fed $\mathrm{C}$ also had a $52.5 \%$ reduction in plasma insulin concentrations compared with AL cows fed C, although DMI was only $12.5 \%$ lower in the former group of cows. Thus, prepartum hypoinsulinemia as a predisposing factor to ovarian cyst development in the present study cannot be completely ruled out. These observations emphasize the need to further investigate the influence of nutritional manipulation of the dry period on metabolic and reproductive hormones, and their association with the postpartum development of ovarian cyst. It is noteworthy that all cows diagnosed with ovarian cyst recovered spontaneously before the first TAI in this study.

Our second hypothesis was also partially supported in that the source of dietary fatty acid supplemented during the prepartum period significantly affected the interval from calving to first postpartum ovulation, with cows fed L or F having a shorter interval than those fed C. The beneficial effects of postpartum dietary fatty acid supplementation on dairy cow reproductive function have been reported in several studies (reviewed by Santos et al., 2008). For example, a diet enriched in linolenic acid decreased pregnancy losses (Ambrose et al., 2006), whereas diets supplemented with either linoleic or linolenic acid accelerated early development of bovine embryos (Thangavelu et al., 2007). Also, in one study (Zeron et al., 2001), intrafollicular concentrations of polyunsaturated fatty acids were higher during winter and this has been linked to increased fertility in dairy cows. However, to our knowledge, the present study is the first one to associate dietary fatty supplementation in the dry period with resumption of cyclicity. Circulating concentrations of IGF-1 are critical to ovarian follicular development (Beam and Butler, 1999) and highly correlated with energy balance during the first weeks of lactation, determining the interval from calving to the first ovulation (Beam and Butler, 1998; Butler, 2000). In the current study, canola-fed cows had higher plasma concentrations of NEFA around parturition and greater BW loss after calving. However, we did not find any differences in energy balance or plasma concentrations of IGF-1 among cows fed C, L, or F either pre- or postpartum, clearly indicating that neither NEBAL nor decreased IGF-1 concentration was a contributing factor to delayed ovulation in cows fed C. The average interval from calving to first ovulation was 35 $\mathrm{d}$ in canola-fed cows, which is comparable to intervals of 31 (Sakaguchi et al., 2004) and 32 d (Gümen et al., 
2005) reported for high-producing dairy cows, based on ovarian ultrasonography. This interval of 30 to $35 \mathrm{~d}$ appears to be the norm for North American Holsteins as confirmed in a recent study (Ambrose and Colazo, 2007) that involved 23 dairy herds in Canada. Based on these previously reported intervals of calving to first ovulation, our present results suggest that prepartum dietary supplementation with L or F reduced the average interval from calving to first postpartum ovulation by approximately 2 wk relative to that of $\mathrm{C}$. The effects of dietary fatty acids on follicle development and resumption of ovarian postpartum cyclicity has been recently reviewed by Santos et al. (2008). Based on the proportion of cyclic cows around $65 \mathrm{~d}$ postpartum, they concluded that the type of supplemental fatty acid, whether more saturated or unsaturated, does not influence resumption of postpartum cyclicity in lactating dairy cows. Our findings do not support the above conclusion. Although the underlying mechanisms are unknown, in our study, the type of supplemental fatty acid fed during the dry period clearly had a carryover effect on the interval from calving to ovulation, with dietary supplementation of linoleic (L) or linolenic (F) acids proving to be more beneficial than a diet enriched in oleic (C) acid. Thus, future studies should be designed to elucidate the role of dietary fatty acids on ovarian function, particularly with reference to resumption of cyclicity.

The incidence of uterine infections was $16.6 \%$ in the present study, which is within the range reported in several studies reviewed by Kelton et al. (1998). It is now accepted that uterine infections are diseases related to immune function, and proper nutritional management during the dry period could reduce their incidence (LeBlanc, 2007). In this context, for every 1-kg decrease in DMI during the last 2 wk of the dry period, cows were nearly 3 times more likely to be diagnosed with metritis (Huzzey et al., 2007). Conversely, in the present study, the incidence of uterine infections among AL cows was significantly higher than that in FR cows, suggesting that reduced DMI during the prepartum period is not a predisposing factor for postpartum uterine infections. Cows fed AL were in a more severe NEBAL than FR cows postcalving and there is some evidence that NEBAL may negatively affect postpartum uterine recovery. In a recent study (Wathes et al., 2007b) the expression of 77 out of 79 immune-related and matrix metalloproteinase (e.g., MMP-1) genes was significantly up-regulated in the uterus of cows with severe NEBAL. Another risk factor for uterine infections is high BCS at calving, with overconditioning being a significant factor associated with increased occurrence of metritis in dairy cows (Kaneene and Miller, 1995). Although not overconditioned, AL cows tended to have a small but significantly greater BCS at calving compared with FR cows; however, it was unlikely that the slight increase in BCS among AL cows was a risk factor for uterine infections in this study. Several studies have reported a negative effect of postpartum uterine infections on the reproductive performance of lactating dairy cows (Huszenicza et al., 1999; LeBlanc et al., 2002; Ambrose and Colazo, 2007). Even though the percent pregnancy to first TAI tended to be lower in cows with uterine infections, fertility in AL cows, wherein the incidence of uterine disease was higher, was not compromised in this study, which is attributable, perhaps, to the low overall incidence of uterine disease.

\section{CONCLUSIONS}

The results of this study suggest that feed restriction and the type of dietary fatty acid during the dry period have carryover effects on postpartum reproductive performance of Holstein dairy cows. In this regard, FR cows during the prepartum period had a lower incidence of uterine infections, yet remained less fertile than $\mathrm{AL}$ cows. In addition, cows fed diets supplemented with L or F ovulated sooner than those fed $\mathrm{C}$, but energy balance and fertility remained unaffected. In conclusion, a $24 \%$ feed restriction during the last 4 wk of gestation increased DMI and reduced NEBAL postpartum but negatively affected pregnancy to first TAI. However, diets enriched in either linoleic or linolenic acids reduced the interval from calving to first ovulation compared with a diet enriched in oleic acid, without a beneficial effect on fertility.

\section{ACKNOWLEDGMENTS}

Research supported by Alberta Livestock Industry Development Fund (\#2005F033R), Alberta Milk, and Alberta Agriculture and Rural Development. The authors thank Pavol Zalkovic (University of Alberta, Edmonton) and Phyllis Pitney (Alberta Agriculture and Rural Development, Edmonton) for technical assistance, and the dairy research unit staff for care and feeding of the cows.

\section{REFERENCES}

Agenäs, S., E. Burstedt, and K. Holtenius. 2003. Effects of feeding intensity during the dry period. 1. Feed intake and milk production. J. Dairy Sci. 86:870-882.

Ambrose, D. J., and M. G. Colazo. 2007. Reproductive status of dairy herds in Alberta: A closer look. Proc. 25th Western Can. Dairy Sem., Advances in Dairy Technology 19:227-244.

Ambrose, D. J., J. P. Kastelic, R. Corbett, P. A. Pitney, H. V. Petit, J. A. Small, and P. Zalkovic. 2006. Lower pregnancy losses in lactating dairy cows fed a diet enriched in $\alpha$-linolenic acid. J. Dairy Sci. 89:3066-3074. 
Beam, S. W., and W. R. Butler. 1998. Energy balance, metabolic hormones, and early postpartum follicular development in dairy cows fed prilled lipid. J. Dairy Sci. 81:121-131.

Beam, S. W., and W. R. Butler. 1999. Effects of energy balance on follicular development and first ovulation in postpartum dairy cows. J. Reprod. Fertil. Suppl. 54:411-424.

Beever, D. E. 2006. The impact of controlled nutrition during the dry period on dairy cow health, fertility and performance. Anim. Reprod. Sci. 96:212-226.

Britt, J. H. 1992. Impacts of early postpartum metabolism on follicular development and fertility. Bovine Pract. 24:39-43.

Butler, W. R. 2000. Nutritional interactions with reproductive performance in dairy cattle. Anim. Reprod. Sci. 60-61:449-457.

Canadian Council on Animal Care. 1993. Guide to the Care and Use of Experimental Animals. Vol. 1. 2nd ed. CCAC, Ottawa, Ontario, Canada.

Chelikani, P. K., J. D. Ambrose, D. H. Keisler, and J. J. Kennelly. 2004. Effect of short-term fasting on plasma concentrations of leptin and other hormones and metabolites in dairy cattle. Domest. Anim. Endocrinol. 26:33-48.

Drackley, J. K. 1999. Biology of dairy cows during the transition period: The final frontier? J. Dairy Sci. 82:2259-2273.

Edmonson, A. J., I. J. Lean, L. D. Weaver, T. Farver, and G. Webster. 1989. A body condition scoring chart of Holstein dairy cows. J. Dairy Sci. 72:68-78.

Garverick, H. A. 1997. Ovarian follicular cysts in dairy cows. J. Dairy Sci. 80:995-1004.

Gümen, A., R. R. Rastani, R. R. Grummer, and M. C. Wiltbank. 2005. Reduced dry periods and varying prepartum diets alter postpartum ovulation and reproductive measures. J. Dairy Sci. 88:2401-2411.

Hayirli, A., R. R. Grummer, E. V. Nordheim, and P. M. Crump. 2002. Animal and dietary factors affecting feed intake during the prefresh transition period in Holsteins. J. Dairy Sci. 85:3430-3443.

Holtenius, K., S. Agenäs, C. Delavaud, and Y. Chilliard. 2003. Effects of feeding intensity during the dry period. 2. Metabolic and hormonal responses. J. Dairy Sci. 86:883-891.

Huszenicza, G., M. Fodor, M. Gacs, M. Kulcsar, M. J. W. Dohmen, and M. Vamos. 1999. Uterine bacteriology, resumption of cyclic ovarian activity and fertility in postpartum cows kept in largescale dairy herds. Reprod. Domest. Anim. 34:237-245.

Huzzey, J. M., D. M. Veira, D. M. Weary, and M. A. G. von Keyserlingk. 2007. Prepartum behavior and dry matter intake identify dairy cows at risk for metritis. J. Dairy Sci. 90:3220-3233.

Johnson, M. M., and J. P. Peters. 1993. Technical note: An improved method to quantify nonesterified fatty acids in bovine plasma. J. Anim. Sci. 71:753-756.

Kaneene, J. B., and R. Miller. 1995. Risk factors for metritis in Michigan dairy cattle using herd- and cow-based modeling approaches. Prev. Vet. Med. 23:183-200.

Kelton, D. F., K. D. Lissemore, and R. E. Martin. 1998. Recommendations for recording and calculating the incidence of selected clinical diseases of dairy cattle. J. Dairy Sci. 81:25022509.

LeBlanc, S. J. 2007. Prevention of postpartum uterine disease. Proc. 25th Western Can. Dairy Sem., Advances in Dairy Technology 19:145-155.

LeBlanc, S. J., T. F. Duffield, K. E. Leslie, K. G. Bateman, G. P. Keefe, and J. S. Walton. 2002. Defining and diagnosing postpartum clinical endometritis and its impact on reproductive performance in dairy cows. J. Dairy Sci. 85:2223-2236.

Littell, R. C., P. R. Henry, and C. B. Ammerman. 1998. Statistical analysis of repeated measures data using SAS procedures. J. Anim. Sci. 76:1216-1231.
Lussier, J. G., P. Matton, and J. J. Dufour. 1987. Growth rates of follicles in the ovary of the cow. J. Reprod. Fertil. 81:301-307.

Peter, A. T. 2004. An update on cystic ovarian degeneration in cattle. Reprod. Domest. Anim. 39:1-7.

Pierson, R. A., and O. J. Ginther. 1984. Ultrasonography of the bovine ovary. Theriogenology 21:495-504.

Pryce, J. E., M. P. Coffey, and G. Simm. 2001. The relationship between body condition score and reproductive performance. J. Dairy Sci. 84:1508-1515.

Pursley, J. R., M. O. Mee, and M. C. Wiltbank. 1995. Synchronization of ovulation in dairy cows using $\mathrm{PGF}_{2 \alpha}$ and $\mathrm{GnRH}$. Theriogenology 44:915-923.

Rabelo, E., R. L. Rezende, S. J. Bertics, and R. R. Grummer. 2003. Effects of transition diets varying in dietary energy density on lactation performance and ruminal parameters of dairy cows. J. Dairy Sci. 86:916-925.

Radostits, O. M., K. E. Leslie, and J. Fetrow. 1994. Herd Health: Food Animal Production Medicine. 2nd ed. W. B. Saunders Co., Philadelphia, PA

Ribadu, A. Y., K. Nakada, M. Moriyoshi, W. C. Zhang, Y. Tanaka, and T. Nakao. 2000. The role of LH pulse frequency in ACTHinduced ovarian follicular cyst in heifers. Anim. Reprod. Sci. 64:21-31.

Roberts, S. J. 1986. Veterinary Obstetrics and Genital Diseases. 3rd ed. David and Charles Inc., North Pomfret, VT.

Sakaguchi, M., Y. Sasamoto, T. Suszuki, Y. Takahashi, and Y. Yamada. 2004. Postpartum ovarian follicular dynamics and estrous activity in lactating dairy cows. J. Dairy Sci. 87:2114-2121.

Santos, J. E. P., T. Bilby, W. W. Thatcher, C. R. Staples, and F. T. Silvestre. 2008. Long chain fatty acids of diet as factors influencing reproduction in cattle. Reprod. Domest. Anim. 43(Suppl. 2):2330 .

Schalm, O. W., and D. O. Noorlander. 1957. Experiments and observations leading to development of the California Mastitis Test. J. Am. Vet. Med. Assoc. 130:199-204.

Thangavelu, G., M. G. Colazo, D. J. Ambrose, M. Oba, E. K. Okine, and M. K. Dick. 2007. Early embryonic development in lactating Holstein cows fed diets enriched in unsaturated or saturated fatty acids. Theriogenology 68:949-957.

Thatcher, W. W., and C. J. Wilcox. 1973. Postpartum estrus as indicator of reproductive status in dairy cows. J. Dairy Sci. 56:608-610.

Vanholder, T., J. L. M. R. Leroy, J. Dewulf, L. Duchateau, M. Coryn, A. de Kruif, and G. Opsomer. 2005. Hormonal and metabolic profiles of high-yielding dairy cows prior to ovarian cyst formation or first ovulation post partum. Reprod. Domest. Anim. 40:460467.

Wathes, D. C., N. Bourne, Z. Cheng, V. J. Taylor, G. E. Mann, and M. P. Coffey. 2007a. Multiple correlation analyses of metabolic and endocrine profiles with fertility in primiparous and multiparous cows. J. Dairy Sci. 90:1310-1325.

Wathes, D. C., M. Fenwick, Z. Cheng, N. Bourne, S. Llewellyn, D. G. Morris, D. Kenny, J. Murphy, and R. Fitzpatrick. 2007b. Influence of negative energy balance on cyclicity and fertility in the high producing dairy cow. Theriogenology 68:S232-S241.

Zeron, Y., A. Ocheretny, O. Kedar, A. Borochov, D. Sklan, and A. Arav. 2001. Seasonal changes in bovine fertility: relation to developmental competence of oocytes, membrane properties and fatty acid composition of follicles. Reproduction 121:447-454. 